\section{From mythological ages to Anthropocene: Nature and human relation}

\section{Mitolojik çăglardan Anthropocene: Doğa ve insan ilişkisi}

\author{
Halide Gamze İnce Yakar ${ }^{1}$
}

\begin{abstract}
Environmental pollution, global warming, reduction of living resources, extinction of species, the energy problem, urbanization, deforestation and ecology issues and so on are the important agenda topic of the mankind in the 21 st century. While fighting with these problems, mankind cannot produce realistic and durable solutions, especially in advanced societies. Adding a mental depth, ethical perspective, and the basic mankind traditions to the contribution of the mankind to the ecological problems through his mind will provide realistic and permanent results. For this reason, we will first examine the concepts of myth and nature and their relation to each other. In this study, we will address the relationship between nature and mankind with a mythological perspective from mythological ages to today's Anthropocene era- huntinggathering, agriculture, urbanization, industrialization periods - and make comparisons and draw conclusions. In addition, we will examine the messages of the myths to identify the historical ecological perspective of Turkish society and produce solutions to the main ecological problems of today. We will examine Book of Dede Korkut and the Duha Koca oğlu Deli Dumrul, which is
\end{abstract}

\section{Özet}

21. yüzyılda, çevre kirliliği, küresel $1 s ı n m a$, yaşam kaynaklarının azalması, canlı türlerinin yok olmasi, enerji sorunu, kentleşme, ormansızlaşma vb. ekoloji sorunları insanlığın en önemli gündem maddelerinden birkaçıdır. $\mathrm{Bu}$ problemlerle mücadele ederken insanlik, özellikle de gelişmiş toplumlar- gerçekçi ve kalıcı çözümler üretememektedir. İnsanoğlunun akliyla ekolojik problemlere sunduğu katkıya, ruhsal bir derinlik, etik bir bakış açısı ve temel insanlık geleneklerini eklemek, gerçekçi ve kalıcı sonuçlar ortaya koyacaktır. Bu nedenle, öncelikle mit ve doğa kavramlarını ve bu kavramlarının birbirleri ile olan ilişkisini inceleyeceğiz. Daha sonra çalışmamızda, mitolojik çağlardan günümüz Anthropocene çağına kadar - avc1lılık-toplayıcılık, tarım, kentleşme, endüstrileşme dönemlerindeki doğa ve insan ilişkilerini, mitolojik bir bakış açısıyla ele alacak, karşılaştırmalar ve çıkarımlar yapacağız. 12.-13. yüzylllarda Anadolu'nun doğusundaki Oğuz Türklerinin yaşamını ve dünyaya bakış açısını arı bir dille anlatan Dede Korkut Destanını ve Destandaki on iki hikâyeden biri olan Duha Koca oğlu Deli Dumrul'u, doğa ve insan ilişkileri bağlamında inceleyeceğiz. Ayrıca Türk toplumunun tarihsel ekolojik bakış açısını belirlemek ve bugünün

\footnotetext{
1 Dr. Öğr. Üyesi, Okan Üniversitesi, İnsan ve Toplum Bilimleri Fakültesi, Türk Dili ve Edebiyatı, gamze.yakar@okan.edu.tr
} 
one of the 12 stories in that Book in terms of nature and human relations, which express the perspective of Oghuz Turks life and point of view to the world, whose situate at the east of Anatolia between 12th and 13th century. Starting from the myths, we will compare the contemporary ecological perspectives -deep, superficial, social ecology etc.- with the relation of people with nature in the mythological eras. In our study, it is also possible to find answers to these questions with Duha Koca Oğlu Deli Dumrul Tale: "How is the nature-human relationship in the mythical period?", "How did the mythological age man approach the present state of the problems we are experiencing today?", "What are the basic elements of man in relation to nature?", "Is it possible to reduce human harm to nature and to bring ethical values away from personal interests in relation to nature?", "How is an effective nature education provided?"

Keywords: Nature; Mythology; NatureHuman; Ecology; Dede Korkut.

(Extended English summary is at the end of this document) temel ekoloji sorunlarına çözüm üretmek için de mitlerin bize sunduğu mesajları ele alacağız. Mitlerden yola ç1karak bugünün ekoloji anlayışlar1 - derin, sığ ve toplumsal ekoloji vb. - ile mitolojik çağlardaki insanların doğayla olan ilişkilerini karşılaştıracağız. Çalışmamızda ayrica Duha Koca Oğlu Deli Dumrul Hikâyesi ile, "Bugün yaşadığımız ekolojik sorunların benzerlerine mitolojik çağın insanı nasıl yaklaşmışır?”, “İnsanın doğa ile olan ilişkisindeki temel unsurlar nelerdir?", "İnsanın doğaya verdiği zararı azaltmak ve doğayla olan ilişkisinde kişisel çıkarlardan uzak, etik değerler ortaya koymak mümkün müdür?", "Etkili bir doğa eğitimi nasıl sağlanır?” sorularına da cevaplar bulmak mümkündür.

Anahtar Kelimeler: Doğa; Mitoloji; Doğainsan; Ekoloji; Dede Korkut.

\section{Giriş}

Toplumların iletişsim biçimlerini, hayata bakış açılarını ve geleceklerini belirleyen en temel unsurlardan biri; bu toplumun içinde bulunduğu doğayla olan ilişkisidir. Bugün, ekolojik sorunlara insanlığın geleceğini ve ilerlemesini hiçe sayarak doğanın kurallarına teslim olan derin ekoloji bakış açısı yahut doğaya olan sorumluluklarımızdan sonsuza kadar bizi muaf tutacak materyalist bir bakış açısı ile yaklaşan bir tavır içerisindeyiz. Derin ekoloji anlayışı, doğanın hızlı tahribatını yavaşlatmak için belirli bir süre akılcı ilkeler getirebilecek olsa da her iki bakış açısı da insanlığın geleceğine dair kalıcı çözüm önerileri üretememektedir. Sanayi devriminden sonra doğanın hızlı ve geri dönüşü mümkün olmayan bir biçimde tahrip edilmesi ile başlayan çağa bilim adamları Antroposen (İnsan Çağı) adını verdiler. İnsanlığın doğanın kurallarını kendi menfaatleri doğrultusunda sınırsız biçimde kullandığı bir jeolojik çağ böylelikle başlamış oldu. İnsanın doğaya verdiği zararı azaltmak ve doğayla olan ilişkisinde kişisel çıkarlardan uzak, etik değerler ortaya koymak mümkün müdür? Bugün yaşadığımız ekolojik sorunların başka boyutlarına mitolojik çağın insanı nasıl yaklaşmıştır? Mitsel dönemde doğa-insan ilişkileri nasıldır? Bu sorular çerçevesinde Türk mitolojisinin temel yapıtlarından biri olan Dede Korkut Destanının on iki hikâyesinden biri olan Duha Koca Oğlu Deli Dumrul Hikâyesi çerçevesinde Türklerde doğainsan ilişkisini ve geçmişten bugüne değişen, kaybolan değerleri ortaya koyacağız. 


\section{Mit ve Doğa}

Mitoloji, insanın doğayla uyumunu, ilişkisini sağlar. Doğa olaylarının bilim ile açıklanamadığı bir dönemde, mitoloji insanlı̆̆ın bilinmezlikleri anlamlandırma aracı olmuştur. İnsanlar, doğadaki olayları, kendi eylemleri ile benzerlik kurarak açıklayabilmişlerdir. Bu nedenle de gökyüzünü, bulutları, gök gürültüsünü, güneşi, ayı, okyanusları, depremi, hortumları bile kişileştirmişlerdir (Fiske, 2014: 32). Türklerin en eski inançlarından biri de Gök Tanrı inancıdır. W. Thomsen'e göre, gök bir sonsuzluk olduğuna göre Tanrı da öyle oluşuyordu ve varlığı hayal gücümüze bağlı idi (Akt. Ögel, 2006: 149). Bir doğa unsuru olması itibariyle Gök, insanoğluna bereketi yahut kuraklığ1, soğuğu yahut sıcağı, karanlığ1 yahut aydınlığ1 getiren; sonsuz biçimde yaşamı kaplayan, rahmetine muhtaç olduğuna inanılan bir unsur olmuştur. Bu inancın temelinde de ormana, ağaca, dağa, suya ve hayvanlara kutsallık atfedilmiş ve mitlerle de toplumun doğayla olan ilişkisine yol gösterilmiştir. Kutsallık atfedilen unsura zarar verilmesi düşünülemez. Bu nedenle doğa ile iç içe ve uyumlu bir ilişki kurulmuştur. Gökyüzünün mutlak varlığı, ilkel halkların tanrılarının önemli bir bölümünün yüksekliği, gök kubbeyi, meteorolojik unsurları ifade eden isimler taşımasına neden olmuştur (Eliade, 2017, 105). İnsanlığın ortak aklının, doğanın egemenliği altında ezildiği Paleolitik Çağ'da, doğaya saygı çerçevesinde onun kaynaklarından yararlanmış ve insanda bulunmayan bu Tanrısal güce şükran borçlu olmuşlardır.

Avc1lık toplayıcılık döneminde Türklerin, göçebe veya yarı göçebe yaşam sürdükleri asırlar boyunca güçlü, hareketli ve özgüveni yüksek bir karaktere sahip olduklar1 görülmektedir. Avlanmanın zamanı ve katı kuralları vardır. Bu ideal insan tipini yaratan, tabiatın gereğinden kaynaklanan güç ve kuvvettir. Bu dönemin insanının kişiliklerindeki öfke ve hırs da toplumun doğaya üstün gelme isteğinden doğar (Korkmaz, 2006: 253-254). Mitler, bu dönemde insanların nesnelerin kökenindeki sırrı öğrenmelerini sağlar. Ayrıca nesneler ortadan kaybolduklarında nerede bulunacakları ve nasıl yeniden ortaya çıkarılabilecekleri de mitlerle öğrenilir (Elliad, 2016: 27). Günlük yaşamda bilinmezliklere 1şık tutarak yaşamı kolaylaştırırlar. Mitler, göçebe yaşam tarzından yerleşik yaşam tarzına geçildiğinde toplumların doğa ile ilişkilerinin yapısını da şekillendirmiştir. İnsanlık, doğa olaylarına ortak aklın güveni ve ataların bilgi birikimiyle bakmaya başlamıştır. Bu ortak aklın ve bilgi birikiminin devamı da mitler yoluyla sağlanmıştır. Mitlerle aktarılmak istenen mesajın, öyküdeki yasaklar (hukukî, ahlakî) ve cezalarla ile olduğu gibi öykünün bütününden çıkarılması mümkündür. Mitoloji, insan-doğa ilişkisinde ahlaki bir sistemin nasıl kurulduğunu ve bu sistemin devamı için yapılacakları da gösterir. Ekolojik olanı, toplumsal olan ile birleştirme noktasında mitlerin hayati bir görevi vardır.

Tarımın keşfedilmesi, insan karakterinin ava çıkma ihtiyacını azalttığ1 için daha az güçlü; temel besin kaynağına zorlu bir biçimde ulaşmak zorunda kalmadığı için daha az hareketli ve hırslı biçimde şekillenmesine neden olmuştur. Göçebe yaşamın belirli dönemlerinde, verimli yaşam alanlarına ve kaynağı daha fazla kullanmak için yapısını bozmak yerine farklı kaynak arayışına yönelme, doğanın devamlılı̆̆1 açısından önemlidir. Göçebe yaşam, doğanın insanın egemenliğine girmesine izin vermez (Saydam, 2011: 142). Türklerin doğa ile uyum içindeki yaşamlarının bir göstergesi de kullandıkları hayvan takvimidir. Kent yaşamının başlamasıyla, insanlığın kaynakları daha etkin yönetmesi gerekmiş ve sürekli olarak aynı kaynağı kullandığı için insanoğlunun doğa ile ilişkisi bozulmaya başlamıştır. İnsan, artık kendini doğanın ayrılmaz bir parçası olarak görmez, doğaya hükmetmeyi öğrenmiştir. Birlikte yaşam kültürü, ortak aklın gelişmesini sağlamış, böylelikle doğanın bilinmez güçlerine karşı çareler üretmeye başlamışlardır. İşte bu süreçte, mitolojide değişmeye başlamıştır çünkü artık aynı mitler kentli insanın ihtiyaçlarına cevap verememiştir. Ancak her ne olursa olsun mitler, farklı öykülerle veya aynı öykünün farklı kurgularla anlatılmasıyla yeniden doğmuştur. Yeni din ve felsefe biçimlerinin ortaya çıkması bile insanların mitoloji olmaksızın yapamadıklarını ortaya koymuştur (Armstrog, 2014: 65). 
Endüstrileşmenin başlaması, doğanın kaynaklarının acımasız bir biçimde insanlığın hizmetine sunulması anlamına gelmiştir. İnsanın doğadan uzaklaşması, üretmeye ve daha fazla maddi değere odaklanmasına neden olmuştu. Egemen Batı düşüncesine göre insan, kaynakları kullanmak konusunda tüm canlılardan üstündü; kendi kaderlerine hâkimdi; dünya insanlar için sınırsız firsatlar sağlamaktaydı; insanlık tarihi bir ilerlemeydi (Özerkmen, 2002: 174). Akıl ile gelen aydınlanma, mitleri yararsız ve işlevsiz bulmuştu. Mitler, artık sadece eski zaman hikâyeleriydi. Bu düşünce bugün içinde bulunduğumuz dünyayı kaçınılmaz biçimde sonsuza kadar etkilemiş olacaktır. Bugün yaşadığımız Dünyada mitler, doğanın insana sağladığı manevi, içsel zenginliği hatırlatması; atalarının doğayla bütünleşen yaşamlarını tekrarlayabilmesi anlamında etkili bir eğitim malzemesidir.

Türk toplumuna, bugün kaynakların giderek tükenmeye yüz tuttuğu bir çağda atalarının doğayla olan ilişkilerini mitoloji yoluyla göstererek bugünkü doğa anlayışını biçimlendirme yoluna gidilebilir. Yaşantılarımızda, insanlığın bugünkü akıl gücüne uyum sağlayacak ve onun ruhsal boşluğunu dolduracak bir anlayış geliştiremezsek veya geliştirdiğimiz bu anlayışı kollektif bilince yansıtamazsak dünyayı kaçınılmaz sondan alıkoymak mümkün olmayacaktır. Ekolojideki bütünsellik kuralı nedeniyle, eko sistemdeki tüm canlıların aynı biçimde ve aynı etkileşimle davranması ile doğanın kurtuluşu mümkün olabilir. Bugün, bir ağacı korumakla bir ormanı korumanın birbirinden farklı olmadığını tün insanlığa öğretebildiğimiz bir doğa eğitimi gerekmektedir.

Ekolojik sorunların kültürel bir zeminde çözümlenmesinde felsefenin, edebiyatın özellikle de sözlü kültürün işlevsel bir yeri vardır. Sokrates öncesi filozoflar doğa yorumlarını, dünyayı oluşturan öğelerin eşitliğine, evrensel adalete bağladılar. Doğa unsurları, kişisel gereksinim ve çıkarlara uydurulmak üzere değiştirilebilen kurallar olarak değil, etik bir varlıkbilim öğeleri olarak görülmelidir (Bookchin, 2017: 86). Mitler, içinde bulundukları toplumun felsefi süzgecinden geçerek nesilden nesle aktarılmak üzere oluşturulmuş kültür öğeleridir.

\section{Dede Korkut Destanı ve Doğa-İnsan İlişkisi}

Çalısmamızda ele alacağımız, Dede Korkut Destanındaki hikâyeleri, 9. ve 10. yüzyılda Isıg Göl'ün batısı ile Sırderya Irmağı'nın kuzeyindeki stepler; doğu ve kuzeydoğu Anadolu ile Azerbaycan'dır. Aphaz ili, Azerbaycan, Gürcistan, Kafkasya ve Oğuz ilinde geçer. Şehirler ise Akça Kale, Trabzon, Cızıglar, Derbend, Hamid, Mardin, Sürmelü, Şiregüven, Bayburt gibi bugün de varlı̆̆1 bilinen şehirlerdir (Gökyay, 2003: 11). Destanda, dağları, ormanları, akarsuları, gölleri, bitki örtüsü ve hayvan çeşitliliği ile bu coğrafya cennetin bir kopyası gibidir. Hikâyelerde, halkın geçim kaynakları; avcılık, toplayıcılık ve hayvancılıktır. Doğa ile iç içe bir yaşam tasvir edilir. Öyle ki, doğaya ait pek çok unsurun kişileştirildiği görülür.

Dede Korkut destanının yarı göçebe dünyasında, Oğuzlar aşina olduğumuz yapısında "tabiatmedeniyet" geçişinin bütün problemlerini halletmiş görünmektedir (Abdulla, 2015: 136). Destanda yerleşik hayata geçmiş Oğuzların dünya görüşünden ve yaşayış biçiminden farklı olarak da zengin bir kültür ve yaşam şekli vardır (Korkmaz, 2006: 250-251). Destanda tabiat çok canlı ve coşkun biçimde kendini gösterir. Akan su bile insanları sürükleyip boğan taşkın su anlamındaki "kanlı su "olarak anılır (Ergin, 2000: 6). Eserde, çok zengin tabiat unsurlarından ve hayvanlardan hareketle yapılmış benzetmeler, atasözleri ve deyimler kullanılmıştır. Bu benzetmelerden yola çıkarak bu tabiat unsurlarının ve hayvanların temel karakterlerini ve toplumun günlük hayatında taşıdığ1 değeri anlamış oluyoruz. Oğuz insanı, ananın, babanın, eşin, oğulun, arkadaşın değerini bildiği gibi; hayvanın, doğanın da değerini bilir (Binyazar, 2010: 86). Dede Korkut destanında geçen hayvanların sayısı da bu görüşü ispatlar niteliktedir. Destandaki atlarla ilgili 358; deve ile ilgili 79; koyun ile ilgili 54; boğa ile ilgili 40; ağaçla ilgili 43 söz varlığ1 vardır (Derman ve Aslan, 2016: 211). Göçebe yaşam tarzının özünde bulunan doğayla uyumlu yaşamak, doğanın 
sunduklarına göre yaşamı şekillendirmek, hayatta kalabilmek için doğanın acımasızlı̆̆ıyla mücadele, destanın genelinde toplumun karakterini belirleyen temel unsur olmuştur. Türk destanlarında, ideal insan tipini yaratan; doğadan kaynaklanan güç ve kuvvettir. Yaşadıklanı doğanın sertliği ve acımasızlı̆̆ı, Oğuz insanına akıncı ve savaşçı bir özellik kazandırmıştır (Korkmaz,2006: 253). Doğa, toplumun temel dinamiklerini büyük ölçüde etkilemiştir.

Basat'ın Tepegöz' ü Öldürdüğü Hikâyesinde, düşmandan kaçıp giderken Aruz Koca'nın düşen oğlunu bir aslan bulup götürmüss ve beslemiştir. Bir zaman sonra bu oğlanı ormanda fark edip tekrar Oğuz yurduna getirdilerse de oğlan yeniden aslan yatağına geri dönmüştür. Devreye Dede Korkut girer, oğlanı tekrar tabiata dönmemesi için ikna eder ve ona bir isim verir. İsim verme, tabiattan medeniyete geçişin önemli bir göstergesidir. Bu bölüm tabiata dönüşün mümkün olmadığını, makbul sayılmadığını bildirir. Tabiata dönmek, ateşten, yaşamı kolaylaştıran temel aletlerden, silahlardan kopmak demektir (Abdulla, 2015: 135-137). İnsan öğrenmeye ve öğrendiklerini biriktirip aktarmaya başlamışır ve geriye dönüş hem imkânsız hem de yasaktır.

Sı ̆̆ ekolojik bakış açısı, insanın doğada yarattığı tahribatın durdurulması ve kaynakların korunması için dönemlik politikalar üretirken; derin ekolojik bakış açısı doğadaki bu tahribatın derindeki sebeplerini çözümleyip ilkeler ortaya koymaya çalışır. Ancak bu anlayışa göre doğa insanlara ait değildir (Özer, 2001: 73). Derin ekolojiye göre, doğa insana ait olduğu kadar, diğer türlere de aittir. Mitlerin de işaret ettiği üzere, derin ekolojinin insanı değil doğayı temel alan görüşü, pek çok türle birlikte insanlığın dünyayı algılama biçiminin geçirdiği gelişimi de inkâr etmektir. Insanda bulunan bu üstün akıl gücünü, ruhsal bir denge ile birleştirecek bir güce ihtiyacımız vardır: Mitoloji. İnsan dayanışmasını arttırmak için modern öncesi toplumlarda değerli olanı bulup çıkarırken, aynı zamanda geçmiş ve geleceğin bütün dar kafalı ve bölücü özelliklerini de aşmamız gerekmektedir (Bookchin, 2017: 109).

Uşun Koca oğlu Segrek Hikâyesinde, Kara Tekür'ün yaptırdığ1 koru ve içinde koyduğu kaz, tavuk, geyik ve tavşanlarla Oğuz yiğitlerine tuzak kurduğunu görüyoruz. Ağaçlar ve hayvanlar Oğuz insanı için her zaman cazibe kaynağ1 olmuştur. Salur Ką̧an'in Evinin Yağmalanması Hikâyesi’nde, yurdunu perişan halde bulan Salur Kazan sudan, kurttan -kurt yüzü mübarek sayılmaktadır-, köpekten yardım dilemiştir. Hayvanların, kişileştirildiği görülür.

Bir mitin amacı, insanın doğal bir parçası olan ruhsal boyutun bilincine vardırmaktı. (Armstrong, 2014: 17) Bugün doğanın tüm kaynaklarını sonsuz bir hırsla sömüren insanoğlunun en büyük eksikliği mitsel bir ortamdır. Mitler kaybolduğunda, maddenin soğukluğu ve sevgisizliği ortaya çıkar. Bugün çevre etiğindeki asıl sorun da çevrenin insanın ihtiyaçlarını karşılamasının ötesinde bir değere sahip olmamasıdır (Gül, 2013: 20). Mitolojik anlatılarda verilen cezalar yoluyla, topluma ibret teşkil eder, onu terbiye eder, iyi davranış kazanması için örnek teşkil eder (Abdulla, 2012: 296).

Destanın giriş bölümünde de Dede Korkut, Oğuz toplumuna öğüt verirken yine doğa üzerinden ve doğa ile ilgili öğütler vermiştir. Bu öğütlerde tabiatın yol göstericiliğine olan inanç ve doğayla olan iç içe yaşam dikkat çekmektedir. "Gittikşe yerin otlaklarm geyik bilir. Yesermis yerlerin çimenlerini yaban eşeği bilir. Ayr aym yollarn iżini deve bilir. Yedi kere kokularm tilki bilir. Geceleyin kervan göctü̈̈̈̈nü ana bilir. Erin hafifini ağırm at bilir. Gafil başın ağrsmo beyni bilir. Kolca kopuzyü̈kseltip elden ele, beyden beye ozan gez̧er. Erin cömerdini, erin cimrisini oz̧an bilir. Karşımzda çalip söyleyen oz̧an olsun. Ažp gelen kazayn Tanr savsin hanm hey!" 


\section{Duha Kocaoğlu Deli Dumrul Destanı}

Hikâyenin başlangıcında Deli Dumrul doğanın gereğine aykırı hareket ediyor ve "kuru bir çayın" üzerine köprü yapıyor. Su yaşam kaynağıdır ve bu kaynağı sunan çay kurumuştur. Su, tüm dinsel mitlerde günahları yıkar, arındırır, yeniler (Eliade, 2017: 116). Bu köprü, kuru çayın üzerine yapıldığı için toplumsal bir işleve hizmet etmemektedir. Dumrul, burada doğayı bir çıkar mevzusu olarak kullanmakta, bu köprüden geçenlerden zorla para almaktadır. Üstelik çayın kuru olması, doğanın tükenmişliğini veya işlediği suçların artık affedilmeyeceğini göstermektedir. Doğa, kendisiyle barışık yaşamayan kahramana -ve ailesine- bereket sunmaktan kaçınmaktadır. Bu durum sanki bir felaketin habercisi gibidir. Uşun Koca oğlu Segrek Destaninda ailenin yaşadığ1 kötü dönemden kurtulacaklarını düşündüklerinde Segrek' in annesi şöyle der: "Akıntıl güzel suyun/ Cekilmists çağladı âbir" İnsanoğlu mutlu olduğunda doğa bereketli, doğa bereketli olduğunda insanoğlu mutludur. İnsan ve doğa ayrılmaz bir bütündür. Acaba Dumrul'un tavırlarındaki sertlik ve uyumsuzluk, yaptığ1 köprünün önünde eşkıyalık yapması doğanın tükenmişliğine karş1 içselleştirilmiştir bir tepki olabilir mi? İçine doğduğu bereketli doğanın, imkânlarını ondan çekmeye başlamış olması da onu isyankâr kılmış olabilir mi? Yanlış olan nedir ki doğa kaynaklarını Dumrul'dan esirgemektedir? Destan boyunca coşkun akan su, kanlı su, arı su, soğuk pinar ifadeleri sıkça görülmektedir. Destanın suyun bol olduğu, bereketli bir coğrafyaya ait olduğu düşünüldügünnde suyun kurumuş olması önem kazanmaktadır. Salur Kazan'in Evinin Yağmalandiğg Hikêyede Salur Kazan'ın canlı bir varlık gibi gördüğü su ile konuştuğunu görmekteyiz.

Dumrul, yine doğanın ona sunduğu atına binmekte, doğanıyla avlanmaya çıkmaktadır. Azrail, güvercin olup uçarken, Dumrul, doğan ile güvercin avlamaya gider ancak başarılı olamaz. Pek çok Türk kültürlü halkta olduğu gibi Azerbaycan ve Anadolu'da da güvercin kutsiyet içeren bir kuştur (Kalafat, 2012: 148). Doğan ise hakanların ve yiğitlerin sembolüdür (Ögel, 2006: 127). Doğan gücü ve otoriteyi de temsil eder. Dumrul, barışçıl bir unsura, yırtıcı bir unsurla saldırmışır (Saydam, 2011: 178). Doğaya ait unsurların insanın çıkarları için acımasızca kullanılmaya çalışıldığ1 görülmektedir. Dumrul, birkaç güvercin öldürürse de Azrail'i yakalayamaz. Azrail bu sefer de atının gözüne görünür, at ürker ve Dumrul'u yere atar. Doğa ve unsurları eliyle Dumrul'un aklını başına alması sağlanmaya çalışılmaktadır.

Deli Dumrul, Azrail'den af dilerken onu tanıyamamasını sarhoşluğuna bağlar. Bu sarhoşluğun sebebini de dağlardaki bağlarda yetişen kara salkımlı üzümlerden elde edilen şaraba bağlar. İçki içtiği için sarhoş olması nedeniyle ne söylediğini bilmediği gibi bir bahanenin arkasına sığınır. Doğa, burada Dumrul tarafından kötücül olmakla suçlanmıştır. Oysa Dumrul, doğanın bir nimet olarak sunduğunu, iradesini ortadan kaldıran bir unsura dönüştürmüştür.

Dumrul'un Azrail'den aman dilerken bahsettiği, bağlardaki kara salkımlı üzümlerden şarap yapılması; yarı göçebe yahut yerleşik hayata geçildiği bir döneme işaret etmektedir. Bu nedenle bu hikâyede, göçebe yaşam anlayışından uzak, tabiat-medeniyet geçişini tamamlamıs, doğayı miras olarak bırakan, yerleşik yaşamdaki doğaya egemen olan karakterler vardır.

Tavla tavla koç atlar, doğan, güvercin, katar katar deve, ağıllarda beyaz koyunlar, alaca yılan gibi özellikle de sayılarının fazlalığıyla dikkat çeken pek çok hayvan ve tepesi büyük kara dağlar, soğuk pınarlar, yaylalar, bağlar gibi bereketli yaşam alanları dikkat çekmektedir. Deli Dumrul da, babası da bu hayvanlara ve topraklara sahip oldukları için övünmektedirler.

Dumrul'un babası içinde yaşadığı doğayı yalnızca kendisine hizmet edecek bir unsur olarak görmektedir. Zira kendisinden can isteyen oğluna, can1 yerine sunduğu ilk şey hizmetine aldığ1 doğanın unsurlarıdır. Oğlu doğduğunda dokuz erkek deve kestiğini, koyunlarını da Azrail'in şöleni için kesebileceğini söyler. Azrail'e de canı yerine, "benim" diye nitelediği kara dağı, pınarları, atları, 
develeri, koyunları -tüm varllğını- vermeyi teklif eder. Babası, doğaya hükmettiğini göstererek kibirlenmektedir.

Dumrul da, babasının sözlerine çok benzer bir şekilde, ölümünden sonra kullanması için eşine yayla olarak kara dağları, içmesi için soğuk suları, binmesi için atları, yük taşıması için develeri, şölenlerde yiyebilmesi için koyunları bırakmaktadır. Sahiplendiği doğaya ait unsurları karısına miras olarak bırakmaktadır.

Dumrul'un eşinin söyledikleri ise kendisine ölümünü haber veren ve doğanın sunduklarını miras bırakan eşine bir haykırış niteliğindedir. Eşi öldükten sonra kara dağların, yaylaların, soğuk suların, tavla tavla koç atların kendisi için hiçbir anlam ifade etmediğini ve Dumrul için canını verebileceğini söyler. Dumrul, eşinin sevgisi ile aydınlanır ve Tanrıya alırsa ikisinin canını beraber alması, bırakırsa da ikisinin canını beraber bırakması için yalvarır. Tanırı, Dumrul'un annesinin, babasının canını alır. Dumrul ile eşine 140 yıl ömür verir.

Destan karakterlerinin doğa ile ilişkilerini inceleyerek bir insanın karakter yapısını ve toplum içindeki yerini öğrenebiliriz. Doğa ile uyumlu ve dengeli bir ilişki içindeki insan, ailesinde ve toplumda da aynı dengeyi gözetecektir. Dumrul, kuru bir çayın üzerine köprü yaparak, doğan ile güvercin avlayarak, dağlardaki kara salkımlı bağlardan iradesini ortadan kaldıran bir unsur yaratarak, babası gibi doğaya ait unsurları kişisel malı gibi miras bırakarak doğayla uyumlu ve dengeli bir karakter sergileyememektedir. Babası, annesi, eşi ve diğer insanlarla olan ilişkisinde de barış̧̧ıl, uyumlu ve dengeli değildir. Doğaya ait unsurları kişisel malı olarak sahiplenip eşine miras bırakması, babasından öğrendiği bir davranıştır. Doğa ile uyumlu ve dengeli yaşam, özellikle modern öncesi toplumlarda ailede kazanılan bir davranıştır. Bu nedenle destanda bu bilinci aktaramayan Dumrul'un ailesi ceza almıştır.

İnsan, içine doğduğu doğanın bir parçasıdır. İnsanın olduğu kadar ağacın, suyun, kurdun, kuşun, atın da bu doğada yaşam hakkı vardır. İnsan, doğadaki tüm varlıklarla eşit değere sahiptir. Doğada kendisinin kıymeti bilindiği ölçüde insana her anlamda hizmet etmektedir. Ne toplum ne de doğa bir diğerinin içinde yok olur. Toplumsal ekoloji her birinin bütünselliğini yadsımadan toplumsal olanı ekolojik olanla birleştirerek ahlaki bir süreklilik kazandırmaya çalışır (Bookchin, 2017: 107). Oğuz insanı doğa unsurlarını kişileştirir, onlara toplumun bir ferdi gibi değer verir. Destanın genelinde, doğaya sayg1 duyma kayg1sı güdülmez. Doğa zaten Tanrısal bir güce sahiptir ve ona saygı duymak kaçınılmazdır.

Dede Korkut, destandaki tüm hikâyelerin sonunda hikâyedeki olaylara ilişkin dualar etmektedir. Ancak on iki hikâyeden oluşan bu destanın yedi hikâyesinin sonunda Dede Korkut tarafindan edilen duada, doğanın devamına ilişkin bilgece bir dilek vardır. Toplumun en saygın bireylerinden biri olan Dede Korkut, Oğuzlar için Duha Koca oğlu Deli Dumrul hikâyesinde de "Yerli Karadağlarm yıkılmasın! Gölgeli koca ăgacm kesilmesin! Taşkın akan suyun kurumasın! Kadir Tanr seni namerde mubtaç etmesin.” sözleriyle dua etmektedir. Bu duada, Dede Korkut doğanın bereketini eksik etmediği bir dünya dilediğinde bulunmuştur. Bu dua aynı zamanda doğa ile uyum içinde olunması için de bir uyarıdır. Gereği yapılmadığı takdirde Oğuzları bekleyen sonuç da verilmiştir.

\section{SONUÇ}

Dede Korkut Destanından ve bu destandaki Duha Kocaoğlu Deli Dumrul Hikâyesinden hareketle doğa- insan ilişkisinde; ölümlü insanın, ölümsüz doğaya sahip olamayacağını sadece doğa ile uyum içinde yaşayarak onun sunduğu firsatlardan yararlanabileceğini görüyoruz. $\mathrm{Bu}$ fırsatlar, doğru ve akılcı şekilde toplum yararına kullanılmalıdır. Doğru kullanılmayan doğa, insanoğluna zarar da verebilir. İnsan doğanın sadece küçük bir parçasıdır. Doğaya sahip olduğunu sanıp onu miras bırakmaya kalkan, kaynakları sınırsız biçimde tüketen insanoğlunu da kaçınılmaz 
bir kötü son beklemektedir. Bereketli bir doğa, insanın en büyük şansıdır ve insanoğlu bu şansı korumak için her zaman mücadele etmelidir. Mitlerde, doğanın kaynaklarının azalması ve doğayla uyum içinde yaşamayan bireylerin varlığ ile oluşan olayların sonucundaki durum, gelecek nesillere verilen bir mesaj niteliğindedir. Çocuğuna, doğa ile doğru bir ilişki kurmayı öğretemeyen annebaba hikâyede ölüm ile cezalandırılmıştır. Mitler, bize içinde bulunduğumuz, kaynakların sınırsız biçimde tüketildiği, Anthropocene çağında ruhlarımızda oluşan boşluğu doldurma ve robotlardan farklı olma şansı vermektedir. Çağımız insanının yaşam anlayışına göre yeniden şekillenmiş mitler, doğa ile ilişkimizdeki barışçıl ve adil tarihsel arka planın gelecek nesiller tarafından daha iyi anlaşılmasını sağlar.

\section{KAYNAKLAR}

Abdulla, Kamal. (2015). Gizli Dede Korkut. İstanbul: Ötüken Neşriyat. Armstrong, Karen. (2014). Mitlerin Kısa Tarihi. İstanbul: Alfa Yayınları. Atay, Tayfun. (2005). Göl ve İnsan. Ankara: Kalan Yayınları.

Bayat, Fuzuli. (2012). Türk Mitolojik Sistemi. İstanbul: Ötüken Neşriyat. Binyazar, Adnan. (2000). Dede Korkut. İstanbul: Yap1 Kredi Yayınları.

Bookchin, Murray. (2017). Toplumsal Ekolojisinin Felsefesi. İstanbul: Sümer Yayıncllık. Campbell, Joseph ve Moyers, Bill. (2007). Mitolojinin Gücü. İstanbul: MediaCat Kitapları.

Campbell, Joseph. (2006). İlkel Mitoloji Tanrının Maskeleri. Ankara: İmge Kitabevi.

Derman, Ayşegül ve Aslan, Zeynep. (2016). "Çevre Eğitimi İçin Kültürel Bir Bakış Açısı: Dede Korkut Hikâyeleri”. International Periodical fort he Languages, Literature and History of Turkish or Turkic, 11: 201-220.

Elliade, Mircea. (2017). Kutsal ve Kutsal-Dışı. İstanbul: Alfa Yayınları.

Elliade, Mircea. (2016). Mitlerin Özellikleri. İstanbul: Alfa Yayınları.

Ergin, Muharrem. (2000). Dede Korkut Kitabı. İstanbul: Boğaziçi Yayınları.

Ergun, Pervin. (2000). Türk Kültüründe Ruhlar ve Orman Kültü. Milli Folklor. 87: 113-121.

Fiske, John. (2014). Mitler ve Mitleri Yapanlar. İzmir: İlya İzmir Yayınevi.

Gökyay, Orhan Şaik. (2003). Dede Korkut Hikâyeleri. İstanbul: Dergâh Yayınları.

Gül, Fikri. (2013). İnsan-Doğa İlişkisi Bağlamında Çevre Sorunları ve Felsefe. Pamukkale Üniversitesi Sosyal Bilimler Enstitüsü Dergisi. 14: 17-21.

Gürsoy, Ülkü. (2012). Türk Kültüründe Ağaç Kültü ve Dut Ağacı. Türk Kültürü ve Hacı Bektaş Veli Araştırma Dergisi. 61: 43-54.

Kalafat, Yaşar. (2012). Türk Kültürlü Halklarda Mitler. Ankara: Berikan Yayınevi.

Karçı̆̆a, Servet. (2016). "Dede Korkut Kitabı'nda Hayvanla İlgili Kelimelerin Tasnifi". Uluslararası Türkçe Edebiyat Kültür Eğitim Dergisi. 5: 12-33.

Korkmaz, Zeynep. (2006). “Dede Korkut Hikâyelerinde İnsan ve Doğa”. Türk Dili. 657:250-257. Ögel, Bahaeddin Ögel. (2006). Türk Mitolojisi. Ankara: Türk Tarih Kurumu.

Özarslan, Metin. (2003). “Türk Kültüründe Ağaç ve Orman Kültü”. Türkbilig. 5: 94-102.

Özer, M. Akif. (2001). "Derin Ekoloji”. Çağdaş Yerel Yönetimler. 4: 61-79.

Özerkmen, Necmettin. (2002). İnsan Merkezli Çevre Anlayışından Doğa Merkezli Çevre Anlayışına, Ankara Üniversitesi Dil Tarih Coğrafya Fakültesi Dergisi. 42: 167-185.

Saydam, M. Bilgin (2011). Deli Dumrul'un Bilinci. İstanbul: Metis Yayıncilık. 


\section{Extended English Summary}

Environmental pollution, global warming, reduction of living resources, extinction of species, the energy problem, urbanization, deforestation and ecology issues and so on are the important agenda topic of the mankind in the 21 st century. While fighting with these problems, mankind cannot produce universal, workable, realistic and durable solutions, especially in advanced societies. Adding a mental depth, ethical perspective, and the basic mankind traditions to the contribution of the mankind to the ecological problems through his mind will provide realistic and permanent results. We need the power to combine the superior intelligence of man with a spiritual balance: Mythology. Mythology also shows how a moral system in relation to man-nature is established and what is to be done for this system. Myths have a vital task at the point of combining the ecological with the social. Myths in the world we live today remind us of the spiritual, inner richness that nature provides to man; is an effective educational material for the ancestors to repeat their nature-integrated lives. For this reason, we will first examine the concepts of myth and nature and their relation to each other. Scientists named it the Anthropocene (Human Age), which began with the destruction of nature after an industrial revolution in a way that was impossible and irreversible. A geological age in which humanity used the laws of nature in an unlimited manner in the interests of its own was thus started. In this study, we will address the relationship between nature and mankind with a mythological perspective from mythological ages to today's Anthropocene era- hunting-gathering, agriculture, urbanization, industrialization periods - and make comparisons and draw conclusions. In addition, we will examine the messages of the myths to identify the historical ecological perspective of Turkish society and produce solutions to the main ecological problems of today. We will examine Book of Dede Korkut and the Duha Koca oğlu Deli Dumrul, which is one of the 12 stories in that Book in terms of nature and human relations, which express the perspective of Oghuz Turks life and point of view to the world, whose situate at the east of Anatolia between 12th and 13th century. Starting from the myths, we will compare the contemporary ecological perspectives -deep, superficial, social ecology etc.- with the relation of people with nature in the mythological eras. In our study, it is also possible to find answers to these questions with Duha Koca Oğlu Deli Dumrul Tale: "How is the nature-human relationship in the mythical period?", "How did the mythological age man approach the present state of the problems we are experiencing today?", "What are the basic elements of man in relation to nature?", "Is it possible to reduce human harm to nature and to bring ethical values away from personal interests in relation to nature?", "How is an effective nature education provided?" We can learn the character structure of a person and its place in society by examining the relation of epic characters with nature. It will be balanced in the human family and society, which is a harmonious and balanced relationship with nature.

Dede Korkut Epic and this epic Duha Kocaoğlu Deli Dumrul story in the nature-human relationship; mortal man can not have immortal nature; we live in harmony with nature and can benefit from the opportunities that it offers. These opportunities must be used to the benefit of society in a correct and rational way. If the resources of nature are not used correctly, it can also harm human beings. Human beings are only a small part of nature. Human beings who think that they have nature and inherit it and consume resources in an unlimited manner also expect an inevitable bad end. A fertile nature is man's greatest chance, and mankind must always struggle to preserve this chance. In myths, the result of the decline of the resources of nature and the existence of individuals who live in harmony with nature is a message given to future generations. The parents, who can not teach their children to make a right relationship with nature, are punished with death in the story. Myths give us the chance to fill in the void that exists in our souls in the Anthropocene era and to be different from the robots that we have in us, resources are consumed in an unlimited fashion. The myths reshaped according to the life concept of our contemporaries provide a better understanding of the peaceful and fair historical background of our relationship with nature by future generations. 